\title{
Fabrication of Flat Tubular Clay-Based Porous Support Filters
}

\author{
Dolgorjav Rentsendavaa ${ }^{1,}$ Saran Galdansambuu ${ }^{2, *}$ Song In-Hyuck ${ }^{3}$ \\ ${ }^{1}$ Department of Chemical Engineering, School of Applied Sciences, Mongolian University of Science and \\ Technology, Ulaanbaatar, Mongolia \\ ${ }^{2}$ Center of Material Science, Mongolian University of Science and Technology, Ulaanbaatar, Mongolia \\ ${ }^{3}$ Ceramic Materials Division, Korean Institute of Material Science, 797, Changwon-daero, Korea \\ "Corresponding author. Email: gsaran@must.edu.mn
}

\begin{abstract}
Mongolia has few freshwater resources. It is therefore important to conserve water resources. An efficient possibility is to purify water and reuse it. Therefore, the scientists from the Material Science Center of the Mongolian University of Science and Technology collaborated with the researcher from the Korea Institute of Material Science and carried out a project between 2017-2020. In this study, Mongolian zeolites and prepared kaolin were used and flat tubular porous support was extruded by a double screw vacuum extruder at KIMS. The supports were burned at 800 and $1000^{\circ} \mathrm{C}$ and the properties such as pore distribution were determined by mercury porosimetry. The zeolite-kaolin support had a bulk density of $1.46 \mathrm{~g} / \mathrm{cm}^{3}$, a porosity of $41.52 \%$ and, an average pore size of $218 \mathrm{~nm}$. With its water permeability of $115 \mathrm{~L} / \mathrm{m}^{2} \cdot \mathrm{h}$ at $0.01 \mathrm{MPa}$ and $970 \mathrm{~L} / \mathrm{m}^{2} \cdot \mathrm{h}$ at 0.08 $\mathrm{MPa}$, the support achieved good results. The wastewater treatment tests show that these membranes also have good compressive strengths. We have cleaned the sewage from a leather factory, which was very highly contaminated and has high viscosity.
\end{abstract}

Keywords: Zeolite, Kaolin, Ceramic membrane

\section{INTRODUCTION}

In the past 35 years, environmental issues have become a more acute pressing matter in Mongolia. In particular, the issue of clean water is a priority due to mining. Because there is a lack of clean water in many other parts of the world as well, scientists not only in Mongolia are constantly researching the purification and reuse of water [1]. There are different water treatment technologies, such as membrane technology, activated sludge, adsorption technology, mechanical oxidation ponds, stabilization ponds, trickling filters, rotating biological contactor, and the combination of activated sludge and trickling filters, etc. [2]. As of today, membrane technology is already tried and tested alternative to classical methods of municipal and industrial wastewater treatment in many countries. In addition to the classical material separation operation such as distillation, extraction, and absorption, membrane filtration has developed into a new separation process in recent years, which in principle used for all fluid media but has been widely used for water treatment. The most used materials for membranes are polymer and ceramic materials. Polymeric materials are cheap but have a short service life and low-temperature resistance compared to ceramic materials. Ceramic materials are expensive but have many advantages such as fouling resistance, high-temperature stability, and low maintenance requirements contributing to lower life-cycle costs in such systems. As a raw material for the support of the ceramic membrane's kaolin, aluminum oxides, zirconium oxides, etc. are used [3]. Because of the high cost of synthesizing materials such as aluminum oxides, zirconium oxides, scientists aim to use natural clay to produce low-cost ceramic membranes. There are many studies to prepare ceramic support from natural clay with 
different pore-forming agents [4]. Nabali et al. prepared ceramic support from natural kaolin clay with $28 \mathrm{wt} \%$ limestone as pore-forming agent [5]. Natural clay-based support is prepared with 0-30 wt\% of starch by Sonia Bouzid Rekik et al [6]. Omar Samhari et al. obtained microfiltration membranes from Moroccan natural kaolinite clay and corn starch as a porosity agent [7]. Their experimental results showed that the membrane prepared with $10 \mathrm{wt} . \%$ of corn starch is considered as an optimized membrane, which has an average pore size of $2.3 \mu \mathrm{m}$ and a mechanical strength of $20.2 \mathrm{MPa}$.

It is also important to improve the membrane properties made with natural kaolin. For example, Shaheen Fatima Anis et al. have a new electroceramic membrane and assessed its resistance to fouling [8]. They have produced three different ratios of zeolite and carbon nanostructures, initially with 60,70 , and $80 \%$ by weight of zeolite. The carbon nanostructures and the binder were made in a ratio of $1: 1$. These types of composite membranes have selfcleaning properties that achieve a high level of flux decline.

The researchers from the Persian Gulf University in Iran and the Department of Civil and Environmental Engineering of the Florida International University worked on the development of an innovative two-layer tubular ceramic membrane with improved separation properties, high mechanical and thermal stability using affordable and easily accessible raw materials [9]. These researchers have the clay-based ceramic support membrane was fabricated by extrusion technique using kaolin, alumina, and natural zeolite. The support membrane was then coated with the natural zeolite and activated carbon using the crossflow filtration technique to prepare the two-layer microfiltration membranes of MF-Z and MF-C.

Zeolites are alkali metals and hydrated aluminosilicates that come in two types: natural and artificial. Zeolite is an aluminum silicate compound with a hollow space and a crystalline lattice structure containing large ions and free water molecules capable of ion exchange and dehydration. Natural zeolites are not inferior to synthetic zeolites in their ion exchange, adsorption, and catalyst properties, but are more resistant to high temperatures, acids, and alkalis [10]. The ion exchange capacity of zeolite depends on the isomorphism of the crystalline structure, the charge, size, and hydration capacity of the ion being exchanged. The speed of the ion exchange process depends on the diameter of the inlet window, and the speed increases as the diameter of the inlet window increases. Compared to other natural adsorbents, zeolite has the ability to selectively adsorbate, so it is important to study its porous structure for use as an adsorbent. For this reason, zeolite is used and researched in many areas of industry.

\section{EXPERIMENTAL}

In this study, low-cost and abundantly accessible raw materials from Mongolia including kaolin, natural zeolite was used to develop the ceramic membranes. We used primary kaolinite from MandalOvoo for our investigation. The Mandal-Ovoo deposit of kaolinite is found in Umnugobi province, located $450 \mathrm{~km}$ from Ulaanbaatar. In this deposit, the kaolinite can be mined in an open pit. Zeolite samples were selected from Urgun sum in Dornogovi province, $94 \mathrm{~km}$ southeast of Sainshand and $540 \mathrm{~km}$ from Ulaanbaatar, $23 \mathrm{~km}$ from the high voltage line along the railway. For the investigation of kaolin from Mandal-Ovoo and Zeolite from Urgun, the following analysis methods have been conducted: Xray diffraction were recorded on X-ray diffractometer (XRD2200-Rigaku Japan) with $\mathrm{Cu}-\mathrm{K} \alpha$ source operated with the wavelength at $\lambda=1.51418 \AA$ Slit systems, step-size $\left(0.02^{\circ}\right)$, source voltage $(40 \mathrm{kV})$, and current $(30 \mathrm{~mA})$ were kept constant during the scans that were conducted in $\theta-2 \theta$ coupled mode, and chemical analysis was carried out by the X-ray fluorescence analysis at the Korea Institute of Material Science (KIMS). Primary kaolinite contains sand and dust, so we processed kaolinite. MandalOvoo primary kaolinite was prepared as follows [11]. First, the kaolin was crushed and then mixed with water to form a suspension. After 2 days, the suspension was sieved with a $0.3 \mathrm{~mm}$ sieve to remove large stones. The suspension was then left to rest for 2-3 days so that the kaolin could sediment. After the kaolin had sedimented, the excess water was pumped off. The sludge was dehydrated with a filter press. Dehydrated kaolin was dried at $110^{\circ} \mathrm{C}$ for $24 \mathrm{~h}$ and, after drying, ground and sieved with a $0.063 \mathrm{~mm}$ sieve. Natural zeolite was ground with a jaw crusher and sieved with a $2 \mathrm{~mm}$ sieve.

To extrude the zeolite-kaolin support layers, 10 wt.\% of methyl celluloses (Methylcellulose, SigmaAldrich, USA) as a binder, and $40 \mathrm{wt} \%$ of distilled water as a solvent were added. The mixed slurry was aged for $24 \mathrm{~h}$ at room temperature and extruded by a double screw vacuum extruder (KTE-50S, Kosentech O. LTD., Korea) at $18 \mathrm{MPa}$. After the extrusion, the moist supports were dried at room temperature for 24 h. The extruded and dried supports were burned at 
800 and $1000^{\circ} \mathrm{C}$ for $1 \mathrm{~h}$. The pore characteristics of the supports were investigated by scanning electron microscopy analysis (JSM6700-F, JEOL, Japan), by mercury porosimeter (Autopore IV 9510, Micromeritics, USA), and capillary flow porosimeter (CFP-1200-AEL, Porous Materials Inc., USA). To guarantee the precision of the obtained data, nitrogen and helium (Technoplyn, Linde) were used at 99.9995\% grade.

\section{RESULTS AND DISCUSSION}

Zeolite from Urgun contains $\mathrm{SiO}_{2}-65.98 \%$, $\mathrm{Al}_{2} \mathrm{O}_{3}-13.70 \%$, $\mathrm{TiO}_{2}-0.36 \%, \mathrm{CaO}-1.44 \%, \mathrm{Fe}_{2} \mathrm{O}_{3}-$ $2.25 \%, \mathrm{~K}_{2} \mathrm{O}-2.68 \%, \mathrm{Na}_{2} \mathrm{O}-2.99 \%, \mathrm{P}_{2} \mathrm{O}_{5}-0.09 \%$ and $\mathrm{MgO}-0.96 \%$.

The mineral composition of the samples taken from the Urgun Zeolite deposit is determined and shown in Figure 1.

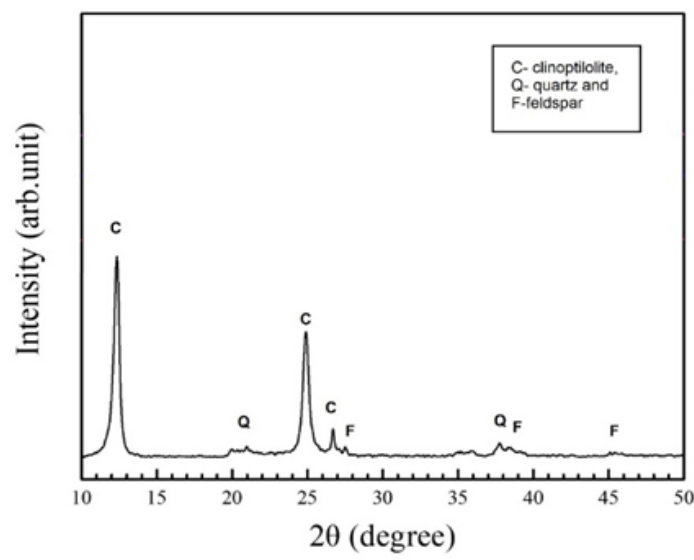

Figure 1. X-ray diffraction patterns of zeolite from Urgun

As a result of X-ray data processing, it was revealed that the Urgun zeolite consists of clinoptilolite $60.9 \%$, quartz $24.24 \%$, and feldspar $9.74 \%$. The SEM image of the zeolite can be seen in Figure 2.

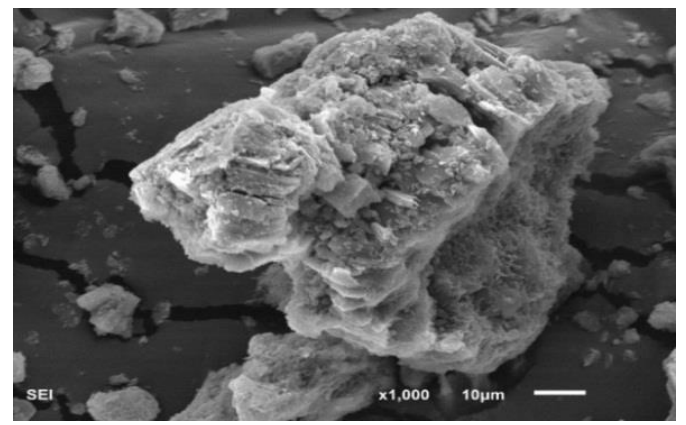

Figure 2. SEM image of the zeolite from Urgun
The physical-mechanical properties of Zeolite are shown in Table 1.

Table 1. Physical-mechanical properties of Zeolite Urgun

\begin{tabular}{|l|l|}
\hline Density, $\mathbf{g} / \mathbf{c m}^{\mathbf{3}}$ & 2.42 \\
\hline Hydrostatic density, $\mathbf{g} / \mathbf{c m}^{\mathbf{3}}$ & 1.46 \\
\hline Porosity, \% & 39.7 \\
\hline Specific surface, $\mathbf{g} / \mathbf{c m}^{\mathbf{2}}$ & 4239.8 \\
\hline
\end{tabular}

The chemical composition of the clay from MandalOvoo is shown in Table 2. We have chosen the kaolin of Mandal-Ovoo because it sinters well and makes a good ceramic body.

Table 2. Chemical composition of natural clay from Mandal-Ovoo, \%

\begin{tabular}{|l|l|l|l|l|l|l|}
\hline $\mathbf{S i O}_{2}$ & $\begin{array}{l}\mathrm{Al}_{2} \mathrm{O}_{3} \\
+\mathrm{TiO}_{2}\end{array}$ & $\mathrm{Fe}_{2} \mathrm{O}_{3}$ & $\mathbf{C a O}$ & $\mathbf{M g O}$ & $\begin{array}{l}\mathbf{N a}_{2} \mathbf{O} \\
+\mathbf{K}_{2} \mathbf{O}\end{array}$ & Others \\
\hline 67.00 & 20.31 & 2.72 & 1.23 & 0.64 & 2.68 & 5.4 \\
\hline
\end{tabular}

The clay contains $70.09 \%$ hydroglimmer and $7.22 \%$ kaolinite. It contains quartz and feldspar. The clay contains $4.8 \%$ aggregate and clay Mandal-Ovoo contains $3.47 \%$ sand, $26.15 \%$ dust, and $70.38 \%$ clay. Experimental results show that Mandal-Ovoo clay is classified as fine clay. The SEM image of the clay is shown in Figure 3.
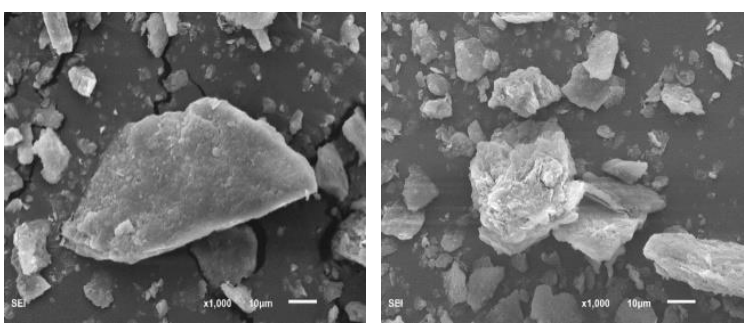

Figure 3. SEM image of the Mandal-Ovoo clay

We have taken the processed kaolin and sieved zeolite for the extruder experiment of the support. We have prepared the support with the following composition and burned it at 800 and $1000^{\circ} \mathrm{C}$ for $1 \mathrm{~h}$.

Table 3. Composition of the batch for supports

\begin{tabular}{|l|c|c|c|c|l|}
\hline & Zeolite & Kaolin & Total & Binder & Water \\
\hline Mass, kg & 3.6 & 2.2 & 5.8 & 0.58 & 2.32 \\
\hline Mass, \% & 62.07 & 37.93 & 100 & 10 & 40 \\
\hline
\end{tabular}

First, the raw materials were mixed dry, and gradually the water and starch were added. The mixed slurry was aged for $24 \mathrm{~h}$ at room temperature and extruded by a double screw extruder. 
The morphology of surface and cross-section of treated supporters at 800 and $1000^{\circ} \mathrm{C}$ are observed by SEM images at the Korean Institute for Material Science. Figure 4 shows the SEM image of a flattubular sample burned at $800^{\circ} \mathrm{C}$.

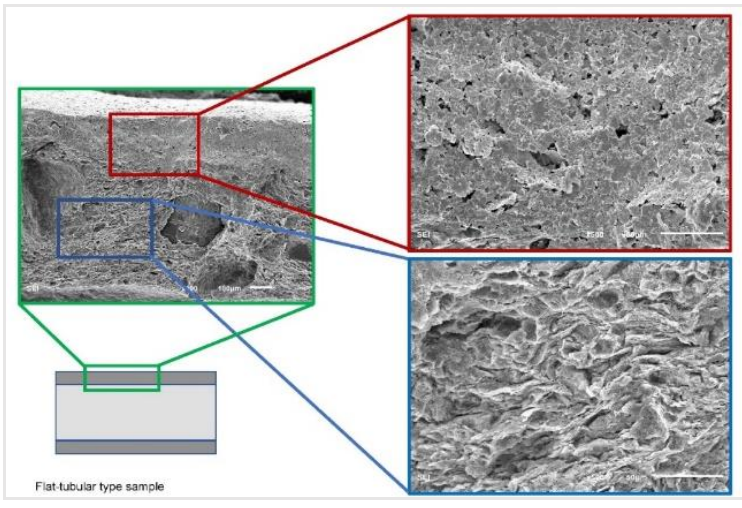

Figure 4. Flat-tubular sample burned at $800{ }^{\circ} \mathrm{C}$

Figure 4 shows that the support membrane is composed of large particles and has a very rough surface with large pores from the surface view. Besides, it can be observed that the support surface has a good distribution of porosity, and therefore it is a suitable candidate for the deposition of the membrane layer.

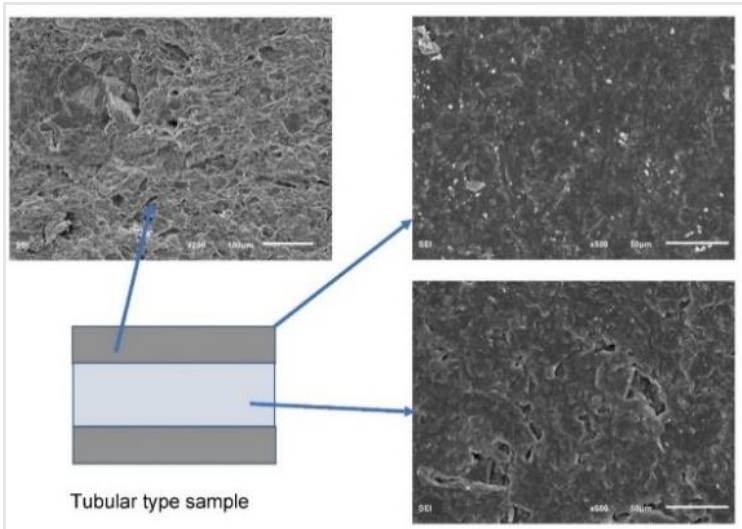

Figure 5. Flat-tubular sample burned at $1000^{\circ} \mathrm{C}$

Figure 5 shows the SEM image of the flat-tubular sample burned at $1000^{\circ} \mathrm{C}$. As can be seen, the carrier is too strongly sintered, which is due to the poor heat resistance of the zeolite. The bulk density of the support was $1.46 \mathrm{~g} / \mathrm{cm}^{3}$ and, the porosity was $41.52 \%$.

The pore size distribution was determined on samples that were burned at $800^{\circ} \mathrm{C}$.

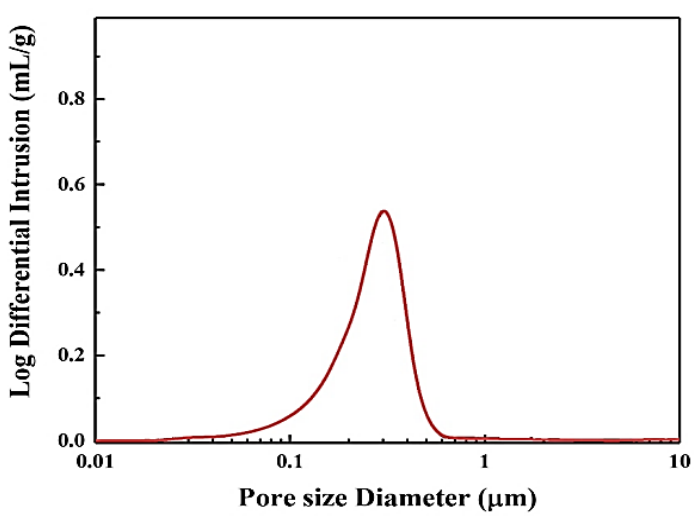

Figure 6. Pore size distribution

From the result of the pore size distribution, it can be seen that the average pore diameter is $0.218 \mu \mathrm{m}$. This means that the membranes will work in the field of microfiltration. We have set up a test stand to measure the permeability of pure water. The structure of the test stand is shown in the following picture (Figure 7).

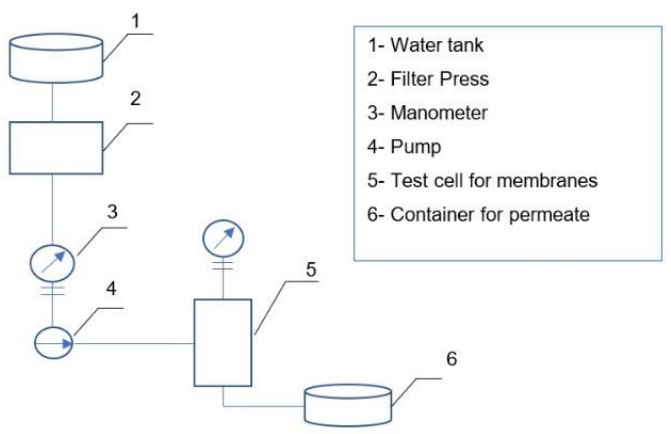

Figure 7. Schematic representation of the test stand

The water permeability was measured at pressures of $0.01 \mathrm{MPa}$ to $0.08 \mathrm{MPa}$. The pure water permeability of the supports for the membrane was systematically decreased with dipping time (Figure 8).

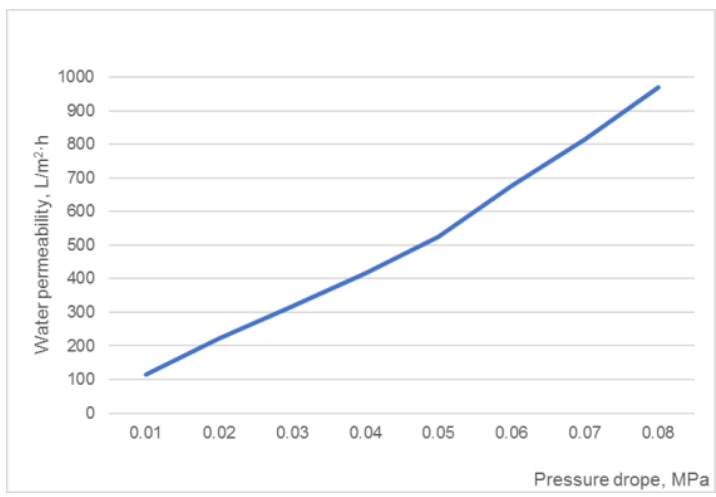

Figure 8. Pure Water permeability of the supports, $\mathrm{L} / \mathrm{m}^{2} \cdot \mathrm{h}$ 
The experiment was carried out at a room temperature of $26^{\circ} \mathrm{C}$. At the pressure of $0.01 \mathrm{MPa}$, the water permeability was $115 \mathrm{~L} / \mathrm{m}^{2} \cdot \mathrm{h}$ and at 0.08 $\mathrm{MPa}$ it was $970 \mathrm{~L} / \mathrm{m}^{2} \cdot \mathrm{h}$.

For the measurement of the wastewater, we want to carry out the following steps.

$\checkmark$ Sedimentation of coarse-grained, mechanical parts in the wastewater

$\checkmark$ Coagulation of the wastewater

$\checkmark \quad$ Filter off the remaining parts with the test filter press.

$\checkmark$ Filtering with the membranes and the measurement of water permeability.

$\checkmark$ Analysis of the purified water.

We are currently working with the Mongolian leather factory Mongol Shivro. We are doing experiments with the wastewater. For the experiment, we brought $80 \mathrm{~L}$ of wastewater from Mongol Shivro. The impurity of the initial wastewater was too high. So, the wastewater is pre-treated by the coagulation process using PAC (polyaluminum chloride).

Coagulation is one of the traditional methods of purifying water. This method is suitable for the treatment of high-polluting water, such as leather, textiles, and wool. Organic pollutants contained in water from these plants are usually stable and stable in small quantities. The reason is that certain types of organic pollutants are surface-active substances. Surface-active substances are pushed out of the hydrophobic group and hydrodynamic groups are drawn to the water and proceeds to form a molecular order structure or emulsion. The other emulsion is stabilized in the interior of the emulsion.
Wastewater containing such small amounts of the emulsion cannot be treated by mechanical methods such as filtration or decomposition. Therefore, it is necessary to distinguish the emulsion using a chemical method, and one of the most widely used emulsion methods is the coagulation method. In the coagulation method, additional reagents or coagulants are used for the separation of the emulsion. The most widely used coagulants are aluminum and ironsoluble salts and polyelectrolytes. From the results of the analysis, the wastewater of the leather industry is transmitted by two sedimentary tanks, a new settling agent, and some of the suspended solids are mixed with other streams. The coagulation test was carried out on the tanks.

However, due to the water pollution and viscosity were too high, the sedimentation caused by coagulation could not be shed. Therefore, the water from the tailings water treatment plant was used as the main research object. Due to the high load of the water from the plant, the amount of added polyaluminum chloride in the range of 0.5 to $5 \mathrm{~g} / \mathrm{L}$ was changed, thereby determining the amount of coagulant. Salts were added to the sewage samples in appropriate amounts and stirred for 10 minutes to dissolve. To reduce the $\mathrm{pH}$ of the samples to 4.3, concentrated sulfuric acid $(96 \%)$ was added. The purifying water $\mathrm{pH}$ is directly related to the amount of PAC added. When the PAC is added to the water, hydrolysis becomes a $\mathrm{pH}<7$, and the higher the PAC is, the lower the $\mathrm{pH}$ value. To complete the coagulation process, $\mathrm{pH}$ should be maintained between $7-8$ and we selected $\mathrm{pH}=7.5$ for our experiment and neutralization using the burned lime. After coagulation, the samples were sedimented and then filtered with the filter press. The following table shows the demand for PAC (polyaluminum chloride) and lime and the main data of purified water.

Table 4. Consumption of PAC (polyaluminum chloride) and lime, and the main data of purified water

\begin{tabular}{|c|c|c|c|c|c|c|c|c|}
\hline \multirow[b]{2}{*}{ № } & \multirow[b]{2}{*}{ Sample } & \multicolumn{7}{|c|}{ Parameters } \\
\hline & & $\mathbf{p H}$ & $\begin{array}{l}\text { Conductivity, } \\
\mathrm{mS} / \mathrm{cm}\end{array}$ & $\begin{array}{l}\text { Suspended } \\
\text { solids, mg/L }\end{array}$ & $\begin{array}{l}\text { COD, } \\
\mathrm{mg} / \mathrm{L}\end{array}$ & $\begin{array}{l}\text { Sulphide, } \\
\text { mg/L }\end{array}$ & $\begin{array}{l}\text { Soluble } \\
\text { salt, mg/L }\end{array}$ & $\begin{array}{l}\text { Chrome, } \\
\text { mg/L }\end{array}$ \\
\hline 1 & $0.4 \mathrm{~g}$ lime, $0.5 \mathrm{~g}$ PAC & 6.77 & 7960 & 176.90 & 5187 & 6.1 & 13410 & 0.84 \\
\hline 2 & $0.4 \mathrm{~g}$ lime, $1 \mathrm{~g}$ PAC & 6.65 & 7730 & 128.75 & 4194 & 15.4 & 13636 & 3.58 \\
\hline 3 & $0.4 \mathrm{~g}$ lime, $1.5 \mathrm{~g}$ PAC & 6.94 & 7670 & 82.5 & 3369 & 3.6 & 13968 & 0.38 \\
\hline 4 & $0.4 \mathrm{~g}$ lime, $2 \mathrm{~g}$ PAC & 6.55 & 7910 & 32.96 & 3163 & 0 & 14960 & 1.2 \\
\hline 5 & $0.4 \mathrm{~g}$ lime, $3 \mathrm{~g}$ PAC & 6.94 & 7650 & 38.11 & 3176 & 6.6 & 13386 & 0 \\
\hline 6 & $0.4 \mathrm{~g}$ lime, $5 \mathrm{~g}$ PAC & 7.17 & 7690 & 38.16 & 3180 & 0 & 13132 & 0 \\
\hline 7 & Filtered by support & 6.95 & 8390 & 11.21 & 1719 & 0 & 15376 & 0.02 \\
\hline 8 & Initial water & 11.10 & 6820 & 515 & 6877 & 163.2 & 9960 & 0.08 \\
\hline 9 & After $\mathrm{pH}=4.3$ & 6.32 & 7370 & 350 & 6400 & 0 & 14720 & 0.04 \\
\hline 10 & General coagulation & 6.81 & 8270 & 250 & 3582 & 0 & 15132 & 0.08 \\
\hline
\end{tabular}


In wastewater, the content of suspended solids was $515 \mathrm{mg} / \mathrm{L}$. After the cleaning of the water, it was reduced to $11.21 \mathrm{mg} / \mathrm{L}$.

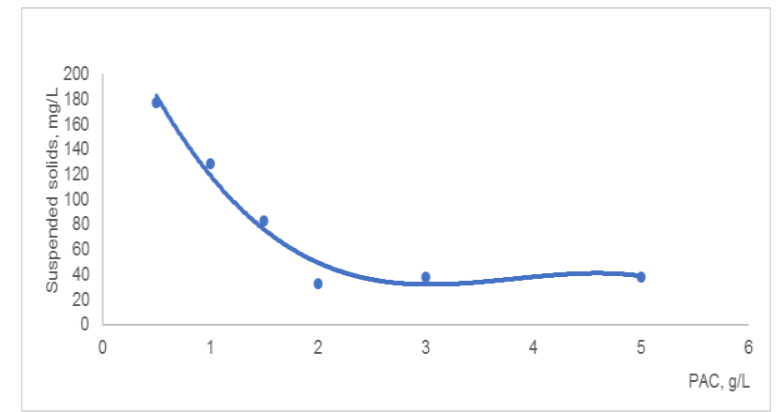

Figure 9. PAC's impact on suspended solids, mg/L

The total amount of COD (chemical oxygen demand) was $6877 \mathrm{mg} / \mathrm{L}$ in sewage and decreased to 1719 $\mathrm{mg} / \mathrm{L}$ after treatment.

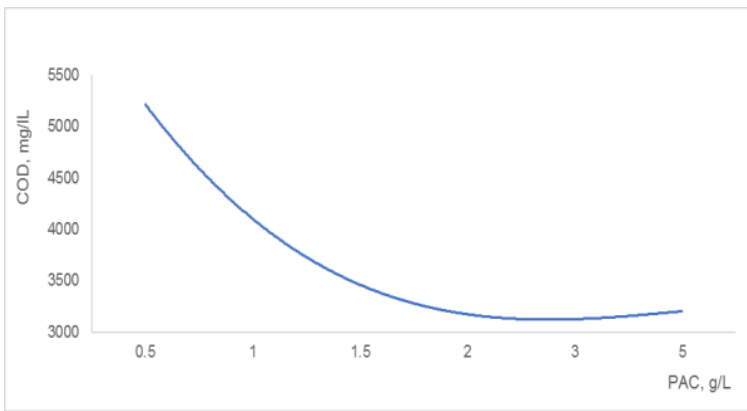

Figure 10. PAC's impact on COD, mg/L

From Figure 10 you can see that with the consumption of PAC (polyaluminum chloride) the amount of COD (chemical oxygen demand) decreases and at $2 \mathrm{~g} / \mathrm{L}$ is lowest. During wastewater filtration, water permeability is reduced as shown in Figure 11.

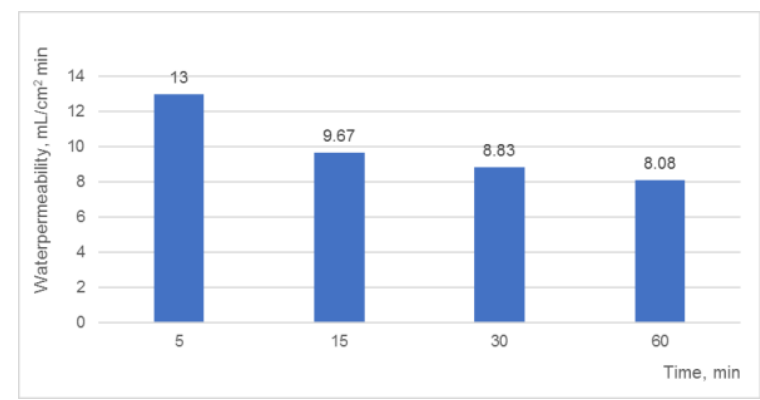

Figure 11. Durability of membranes (pressure drop $0.05 \mathrm{MPa})$

From Figure 11, it can be seen that the water permeability decreases with time. From these results, it can be seen that the membrane supports work well. To clean a lot more we need to optimize the pore size distribution of the supports.

\section{CONCLUSION}

In this study, we have explored the possibility of obtaining zeolite-kaolin composite support with Mongolian raw materials. A porous ceramic support membrane was successfully obtained by a vacuum extrusion process using 37.93\% Mongolian kaolin, $62.07 \%$ natural zeolite from Urgun together with $40 \%$ by weight of water and $10 \%$ by weight of methyl celluloses as a binder. The supports were burned at 800 and $1000^{\circ} \mathrm{C}$ and the morphology and pore size distribution were determined. The average pore diameter of the support was $0.218 \mu \mathrm{m}$, bulk density $1.46 \mathrm{~g} / \mathrm{cm}^{3}$ and the porosity was $41.52 \%$.

The water permeability test was carried out at a room temperature of $26^{\circ} \mathrm{C}$, and good results were obtained. That is why we conducted experiments with sewage from a leather factory. The impurity of the initial wastewater was too high. Therefore, the wastewater is pre-treated by the coagulation process using PAC (polyaluminum chloride). The suspended solids in the wastewater were $515 \mathrm{mg} / \mathrm{L}$, which were reduced to $11.21 \mathrm{mg} / \mathrm{L}$ after cleaning the water in several steps and at the end with zeolite-kaolin supports.

\section{ACKNOWLEDGMENTS}

This research was supported by the KIMS-ASIA project of Korea Institute of Materials Science (KIMS). The authors would like to thank the Korea Institute of Materials Science for their financial support and successful collaboration.

\section{REFERENCES}

[1] Gebrehiwet A.G., (2018) Review on membranes for the filtration of aqueous based solution: oil in water emulsion. Journal of Membrane Science and Technology, Vol. 8(2).

[2] Daniele M., Cynthia H., (2015) Nano-filtration and ultra-filtration ceramic membranes for food processing. Journal of Membranes Science Technology, Vol. 5, 2-13.

[3] Amanmyrat A., Maged F.B., Dorian A.H.H., Aleksander G., (2019) Materials and applications for low-cost ceramic membranes, Membranes, Vol. 9, 105.

[4] Linquan S., Ziyi W., Baoyu G., (2020) Ceramic membranes originated from cost-effective and abundant natural minerals and industrial wastes for broad applications - a review. Desalination and Water Treatment, Vol. 201, 121-138. 
[5] Nabila M., Abdelhamid H., Ferhat B., Lazhar F., Boukhemis B., Abdelkrim G., Noureddine B., (2016) Elaboration and characterization of lowcost ceramics microfiltration membranes applied to the sterilization of plant tissue culture media. Journal of Taiwan Institute of Chemical Engineer, Vol. 59, 79-85. DOI: 10.1016/j.jtice.2015.07.032

[6] Sonia B.R., Jamel B., Andre D., Semia B., (2017) Study of ceramic membrane from naturally occurring-kaolin clays for microfiltration applications. Periodica Polytechnica Chemical Engineering, Vol 61(3), 206-215.

[7] Omar S., Saad A.Y., Murielle R.B., Patrick L., (2020) Fabrication of flat ceramic microfiltration membrane from natural kaolinite for seawater pretreatment for desalination and wastewater clarification. Desalination and Water Treatment, Vol. 194, 59-68.

[8] Shaheen F.A., Boor S.L., Mostafa K., Raed H., (2021) Electro-ceramic self-cleaning membranes for biofouling control and prevention in water treatment. Chemical Engineering Journal, Vol. 415,128395 .

[9] Behrouz J., Mohsen A., Seyed A. H., Mika S., (2020) Elaboration and characterization of novel two-layer tubular ceramic membranes by coating natural zeolite and activated carbon on mullite-alumina-zeolite support: application for oily wastewater treatment. Journal of Asian Ceramic Societies, Vol. 8, 848-86.

[10] Inglezakis V.J., (2005) The concept of "capacity" in zeolite ion-exchange systems. Journal of Colloid and Interface Science. Vol. 281(1), 68-79.

[11] Saran G., (2018) Investigation results of the Mongolian raw materials, KIMS-ASIA second symposium, Ulaanbaatar. 